\title{
Correlation study of GAPDH, Bcl-2, and Bax protein immunoexpression in patients with colorectal adenocarcinoma
}

\author{
Marlena Brzozowa-Zasada ${ }^{1}$, Józef Kurek ${ }^{2}$, Adam Piecuch ${ }^{1}$, Katarzyna Stęplewska ${ }^{3}$ \\ ${ }^{1}$ Department of Histology and Cell Pathology, School of Medicine with the Division of Dentistry in Zabrze, Medical University \\ of Silesia in Katowice, Poland \\ ${ }^{2}$ Department of Surgery, Municipal Hospital, Jaworzno, Poland \\ ${ }^{3}$ Department of Pathology, Institute of Medicine, University of Opole, Opole, Poland
}

Gastroenterology Rev 2018; 13 (4): 322-331

DOI: https://doi.org/10.5114/pg.2018.79813

Key words: colorectal cancer, glycolysis, hypoxia, apoptosis, Bcl-2 proteins.

Address for correspondence: Marlena Brzozowa-Zasada, Department of Histology and Embryology, School of Medicine with the Division of Dentistry, Medical University of Silesia, 19 Jordana St, 41-808 Zabrze, Poland, e-mail: marlena.brzozowa@op.pl

\begin{abstract}
Introduction: Colorectal cancer (CRC) is the third and second most commonly diagnosed cancer worldwide in males and females, respectively. Despite prominent progress in diagnosis and treatment, the recurrence rates are still high. A tumour hypoxic environment leads to an increase in glycolytic metabolism. The crucial intermediate component of glycolysis, glyceraldehyde-3-phosphate dehydrogenase (GAPDH), could play a significant role in cancer progression. An increased level of GAPDH has been described in oncogene-induced transformation and anti-apoptotic function. In other studies, GAPDH has been involved in apoptosis induction.

Aim: We examined colorectal adenocarcinoma samples to assess the immunoexpression of GAPDH protein. We also evaluated the correlation between the expression of GAPDH protein and apoptotic parameters including expression of Bcl2 and Bax.

Material and methods: Paraffin sections were incubated for 60 min with primary antibody against GAPDH, Bcl-2, and Bax.

Results: Results of our study have shown that GAPDH expression in colorectal cancer is upregulated. We revealed significant positive correlation between expression of this protein and grade and size of tumour, and regional lymph node involvement. In the case of apoptosis-associated proteins, e.g. Bcl-2 and Bax, we found negative correlations between expression of these proteins and grade and size of tumour, lymphovascular invasion, and regional lymph node involvement. Finally, we demonstrated that GAPDH up-regulation is connected with down-regulation in Bcl-2 and Bax.

Conclusions: Up-regulation of GAPDH protein and down-regulation of $\mathrm{BCl}-2$ and Bax may result in increased of cancer.
\end{abstract}

\section{Introduction}

It is generally accepted that colorectal cancer (CRC) is an important global health problem. It is the third and second most commonly diagnosed cancer worldwide in males and females, respectively. Despite the prominent progress in diagnosis and treatment, the recurrence rates in the case of CRC are still high [1]. Therefore, the discovery of molecules significant to cancer development and metastasis as well as new therapeutic strategies seems to be very promising for improving the prognosis and therapy of CRC patients [2].

More than 50 years ago, Warburg hypothesised that cancer growth is facilitated by tumours producing their energy by aerobic glycolysis. Recent studies aimed at evaluating this hypothesis have revealed that cancerous cells have adopted their metabolism to facilitate the uptake and incorporation of nutrients needed for proliferation. Tumour development and progression are indeed associated with elevated glucose uptake and its aberrant metabolism [3, 4]. It should be pointed out that tumour hypoxic environment leads to an increase in glycolytic metabolism. The crucial intermediate component of glycolysis, glyceraldehyde-3-phosphate dehydrogenase (GAPDH), could play a significant role in cancer development and progression [5]. GAPDH specifically catalyses the simultaneous phosphorylation and oxidation of glyceraldehydes-3-phosphate to 1,3-bi- 
phosphoglycerate by the use of NADț as the electron acceptor. GAPDH is composed of a polypeptide chain of 335 amino acids. Structural studies characterised two regions, namely the glyceraldehydes-3-phosphate catalytic site and the NADț binding site, a primary structure described as the Rossmann fold, which is also needed for activation of other dehydrogenases $[6,7]$.

As revealed by the studies, an increased level of GAPDH has been described in oncogene-induced transformation, angiogenesis, and anti-apoptotic function [8-11]. In other studies, GAPDH has been involved in apoptosis induction. Nevertheless, the reason for this paradox is poorly understood [12]. For example, differential subcellular localisation of GAPDH may be associated with its opposing biological activities in apoptotic and proliferating hepatocytes. The different functions of GAPDH may also be connected with various levels of post-translational modification of this protein $[13,14]$ However, to our knowledge, there are no studies analys ing the expression of GAPDH with expression of factors connected with apoptosis, especially in the case of cancer development [15].

Apoptosis is of tremendous current interest to clinicians who study and treat cancer. In the case of colorectal cancer, alterations in apoptosis contribute to both the pathogenesis and resistance to chemotherapeutic drugs and radiotherapy, both of which act, at least in part, by killing cancer cells [16]. Previous studies have reported that GAPDH can trigger mitochondrial oxidative stress-mediated cell death controlled by $\mathrm{Bcl}-2$ family proteins [17]. It should be mentioned that there are two classes of $\mathrm{Bcl}-2$ proteins: pro-apoptotic proteins (Bax, Bad, Bid, Bik) and anti-apoptotic proteins (Bcl-2, $\left.B c l-X_{L}, B c l-W\right)$. While anti-apoptotic proteins are involved in apoptosis by delaying the mitochondrial release of cytochrome-c, the proapoptotic proteins activate such releases [18]. Elucidation of the underlying regulatory mechanism seems to be essential not only to disease aetiology but also to treatment. Several types of therapies for cancer, including cytotoxic therapies, depend primarily upon induction of apoptotic cell death. Some authors suggested that abnormal expression of specific apoptosis-related proteins seems to be a major component of chemo-resistance $[19,20]$. It may have significance in the context of hypoxic tumour environment and GAPDH expression, which is a marker of glycolysis.

\footnotetext{
Aim

We examined 60 cases of colorectal adenocarcinoma samples to assess the immunoexpression of GAPDH protein. We also evaluated the correlation between the expression of GAPDH protein and apoptotic parameters including expression of $\mathrm{BCl} 2$ and $\mathrm{Bax}$.
}

\section{Material and methods \\ Collection of tumour samples}

Sixty formalin-fixed, paraffin-embedded tissue specimens of primary colorectal adenocarcinoma were retrieved from archival material (Chair and Department of Pathomorphology, Medical University of Silesia, Zabrze, Poland). Paraffin-embedded tissue sections taken from postoperative material were diagnosed using standard haematoxylin and eosin staining, and the histological diagnoses were established according to the current standards.

\section{Immunohistochemical staining}

Formalin-fixed paraffin-embedded, $3-\mu \mathrm{m}$ tissue sections were mounted onto SuperFrost slides and deparaffinised in xylene and ethanol of graded concentrations. Microwave antigen retrieval was then performed on the sections, which involved boiling the sections in $0.01 \mathrm{~mol} / \mathrm{l}$ citrate buffer $(\mathrm{pH}$ 6.0) in a domestic microwave oven $10 \mathrm{~min}$. Endogenous peroxidase activity was blocked using 3\% hydrogen peroxide in water, and nonspecific staining was blocked by incubation with $5 \%$ bovine serum albumin in PBS for one hour at room temperature. Sections were rinsed with Tris-buffered saline (TBS, Dako, Denmark) and incubated for $60 \mathrm{~min}$ with polyclonal rabbit primary antibody against GAPDH (GeneTex; catalogue number GTX100118; dilution 1 : 3000), monoclonal mouse primary antibodies against $\mathrm{Bcl}-2$ (Dako; clone: 124; dilution 1 : 200), and polyclonal rabbit primary antibody against Bax (Dako; code A3533; dilution 1 : 200). The En-Vision method (Dako En-Vision Kit/ Alkaline Phosphatase detection system) was used according to the manufacturer's instructions. The bound primary antibody was detected using the new Fuchsin Substrate System (DAKO A/S). The primary antibody was omitted from negative control slides. To suppress non-specific staining due to endogenous alkaline phosphatase activity, levamisole was used at a final concentration of $0.2 \mathrm{mM}$. The sections were counterstained with Mayer's haematoxylin.

\section{Evaluation of the IHC variable}

Immunohistochemical reactions for GAPDH, Bcl-2, and Bax were classified into four groups according to the intensity of immunohistochemical reaction: 0 - negative; 1 - weak; 2 - moderate; and 3 - strong. Heterogeneity was defined as the proportion of cancer cells showing a positive reaction to the total number of cancer cells and was graded from 0 to 3 by assessment: 0 demonstrated negative staining; 1 represented less than $10 \%$; 2 represented $10-50 \%$; and 3 represented 
more than $50 \%$ of cancer cells with positive reaction. The results of intensity of staining and heterogeneity were combined and scored as follows: 0 represented negative; 1 and 2 represented low; 3 and 4 represented moderate; and 5 and 6 represented high expression. All sections were independently analysed by two experienced pathologists with no prior knowledge of clinicopathological parameters under a light microscope, and the images were recorded by digital camera.

\section{Statistical analysis}

All statistical analyses were done with the use of Statistica 10 software. To assess differences between the groups, the Mann Whitney $U$ test and Kruskal-Wallis test was used. Results were considered statistically significant at $p<0.05$. The relationships between GAPDH immunoreactivity and the expression of $\mathrm{BCl}-2$ and $\mathrm{Bax}$ were compared using Spearman correlation coefficients.

\section{Results}

\section{GAPDH immunoexpression}

The results of immunohistochemical analysis of GAP$\mathrm{DH}$ protein expression are summarised in Table I and Figure $1 \mathrm{~A}-\mathrm{C}$. The positive expression of this protein in colorectal adenocarcinoma samples was observed in 43 (88.4\%) patients; 19 (31.66\%) patients demonstrated weak staining $(1+)$ with anti-GAPDH antibody whereas $16(26.67 \%)$ patients and 18 (30\%) showed moderate $(2+)$ and strong staining (3+), respectively.

Statistical analysis revealed no correlation between GAPDH immunoreactivity in the main mass of tumour and clinicopathological parameters such as age, gender, tumour location, depth of invasion, and lymphovascular invasion (Table II). Interestingly, a statistically significant relationship was found between GAPDH immunoexpression and grade of tumour (Kruskal Wallis, $p<0.001)$. According to the data presented in Table II, higher expression of GAPDH correlated with poorly differentiated adenocarcinoma (Spearman, $p<$ $0.001)$. Moreover, significant correlation was detected between GAPDH immunoreactivity and size of primary tumour (Mann-Whitney $U$ test, $p=0.011$ ). Tumours exceeding $10 \mathrm{~cm}$ tended to display higher immunoreactivity (Spearman, $p=0.011$ ). A significant association was seen between regional lymph node involvement and GAPDH immunoexpression, suggesting higher expression level $(56.67 \%)$ in "positive patients" (MannWhitney $U$ test, $p<0.001)$.

\section{Bcl-2 immunoexpression}

The results of immunohistochemical analysis of $\mathrm{Bcl}-2$ protein expression are shown in Table II and Fig- ures $1 \mathrm{D}, \mathrm{E})$. Bcl-2-positive staining was observed in 48 (80\%) patients; 16 (26.67\%) patients demonstrated weak staining (1+) whereas $13(21.67 \%)$ and 19 (31.66\%) patients revealed moderate $(2+)$ and strong (3+) staining, respectively.

The results of our study demonstrated no connection between $\mathrm{Bcl}-2$ immunoreactivity and clinicopathological parameters including age, gender, and tumour location (Table III). Importantly, a statistically significant correlation was revealed between $\mathrm{Bcl}-2$ protein immunoexpression and grade of tumour (Kruskal-Wallis, $p<0.001)$. The higher expression of $\mathrm{Bcl}-2$ was associated with well-differentiated cancer (G1) (Spearman $R=-0.580 ; p<0.001)$. Furthermore, significant correlation was detected between $\mathrm{Bcl}-2$ immunoreactivity and depth of invasion (Kruskal-Wallis, $p<0.001$; Spearman $R=-0.573, p<0.001)$. Interestingly, statistical differences were found between the group with T1 and T3 invasion and between the group with $\mathrm{T} 1$ and $\mathrm{T} 4$ invasion. In both cases the higher level of $\mathrm{Bcl}-2$ immunoreactivity was demonstrated in patients with $\mathrm{T} 1$ invasion. Moreover, differences were also shown between the group with T2 and T3 and between the patients with T2 and T4 invasion. In such cases, the patients with T2 demonstrated higher levels of $\mathrm{Bcl}-2$ protein expression. Correlation was also detected between $\mathrm{Bcl}-2$ immunoreactivity and size of primary tumour (Mann-Whitney $U$ test, $p=0.011$ ). Tumours not exceeding $10 \mathrm{~cm}$ tended to display higher immunoreactivity (Spearman $R=-0.565, p=0.011$ ). Statistically significant decrease in $\mathrm{Bcl}-2$ immunoexpression was observed in relation to lymphovascular invasion and regional lymph node involvement. $\mathrm{Bcl}-2$ expression was significantly lower in patients with positive lymph node status in comparison to those without such involvement.

\section{Bax immunoexpression}

The results of immunohistochemical analysis of Bax expression are summarised in Table III and Figures 1 F, G. The positive expression of Bax was observed in 48 (80\%) patients; 21 patients demonstrated weak staining whereas 12 (21\%) and 15 (25\%) patients revealed moderate (2+) and strong staining (3+), respectively.

Statistical analysis demonstrated no association between Bax protein immunoreactivity and age, gender, tumour location, and lymphovascular invasion. A significant correlation was found between Bax expression and grade of tumour (Kruskal-Wallis, $p<0.001$ ). The higher expression level of Bax protein is characteristic for patients with well-differentiated carcinoma (G1) (Spearman $R=-0.388, p=0.002$ ). Moreover, significant correlation was detected between Bax immunoreactivity and depth of invasion (Kruskal-Wallis, 
Table I. The association of GAPDH protein expression with clinicopathological features in CRC

\begin{tabular}{|c|c|c|c|c|c|c|}
\hline \multirow[t]{2}{*}{ Parameter } & & \multicolumn{4}{|c|}{ GAPDH expression } & \multirow[t]{2}{*}{ Statistical analysis } \\
\hline & & Negative & Weak & Moderate & Strong & \\
\hline \multirow[t]{4}{*}{ Age [years] } & $\leq 60$ & 3 & 9 & 7 & 8 & \multirow{4}{*}{$\begin{array}{c}Z=-0.070, p=0.944 \\
R=-0.0004, p=0.998\end{array}$} \\
\hline & & $11.11 \%$ & $33.33 \%$ & $25.93 \%$ & $29.63 \%$ & \\
\hline & $\geq 61$ & 4 & 10 & 9 & 10 & \\
\hline & & $12.12 \%$ & $30.30 \%$ & $27.27 \%$ & $30.30 \%$ & \\
\hline \multirow[t]{4}{*}{ Gender } & Females & 1 & 9 & 10 & 9 & \multirow[t]{4}{*}{$Z=1.241, p=0.215$} \\
\hline & & $3.45 \%$ & $31.03 \%$ & $34.48 \%$ & $31.03 \%$ & \\
\hline & Males & 6 & 10 & 6 & 9 & \\
\hline & & $19.35 \%$ & $32.26 \%$ & $19.35 \%$ & $29.03 \%$ & \\
\hline \multirow[t]{6}{*}{ Location of tumour } & Proxima colon & 4 & 6 & 3 & 7 & \multirow{6}{*}{$\begin{array}{c}H(2.60)=0.258 \\
p=0.879\end{array}$} \\
\hline & & $20.00 \%$ & $30.00 \%$ & $15.00 \%$ & $35.00 \%$ & \\
\hline & Distal colon & 2 & 6 & 8 & 5 & \\
\hline & & $9.52 \%$ & $28.57 \%$ & $38.10 \%$ & $23.81 \%$ & \\
\hline & Rectum & 1 & 7 & 5 & 6 & \\
\hline & & $5.26 \%$ & $36.84 \%$ & $26.32 \%$ & $31.58 \%$ & \\
\hline \multirow[t]{6}{*}{ Grade of tumour } & G1 & 3 & 12 & 4 & 3 & \multirow{6}{*}{$\begin{array}{c}H(2.60)=13.565, p=0.001 \\
1-3,2-3 \\
R=0.456, p<0.001\end{array}$} \\
\hline & & $13.64 \%$ & $54.55 \%$ & $18.18 \%$ & $13.64 \%$ & \\
\hline & $\mathrm{G} 2$ & 4 & 7 & 5 & 7 & \\
\hline & & $17.39 \%$ & $30.43 \%$ & $21.74 \%$ & $30.43 \%$ & \\
\hline & G3 & 0 & 0 & 7 & 8 & \\
\hline & & $0.00 \%$ & $0.00 \%$ & $46.67 \%$ & $53.33 \%$ & \\
\hline \multirow[t]{8}{*}{ Depth of invasion } & $\mathrm{T} 1$ & 1 & 4 & 5 & 3 & \multirow{8}{*}{$\begin{array}{c}H(3.60)=7.966, p=0.047 \\
\sim 2-4 \\
R=0.234, p=0.072\end{array}$} \\
\hline & & $7.69 \%$ & $30.77 \%$ & $38.46 \%$ & $23.08 \%$ & \\
\hline & $\mathrm{T} 2$ & 4 & 8 & 4 & 2 & \\
\hline & & $22.22 \%$ & $44.44 \%$ & $22.22 \%$ & $11.11 \%$ & \\
\hline & T3 & 1 & 5 & 5 & 7 & \\
\hline & & $5.56 \%$ & $27.78 \%$ & $27.78 \%$ & $38.89 \%$ & \\
\hline & T4 & 1 & 2 & 2 & 6 & \\
\hline & & $9.09 \%$ & $18.18 \%$ & $18.18 \%$ & $54.55 \%$ & \\
\hline \multirow{4}{*}{$\begin{array}{l}\text { Size of primary } \\
\text { tumour }[\mathrm{cm}]\end{array}$} & $\leq 10$ & 4 & 17 & 6 & 7 & \multirow{4}{*}{$\begin{array}{c}Z=-2.549, p=0.011 \\
R=0.327, p=0.011\end{array}$} \\
\hline & & $11.76 \%$ & $50.00 \%$ & $17.65 \%$ & $20.59 \%$ & \\
\hline & $\geq 11$ & 3 & 2 & 10 & 11 & \\
\hline & & $11.54 \%$ & $7.69 \%$ & $38.46 \%$ & $42.31 \%$ & \\
\hline \multirow{4}{*}{$\begin{array}{l}\text { Lymphovascular } \\
\text { invasion }\end{array}$} & No & 4 & 10 & 9 & 5 & \multirow[t]{4}{*}{$Z=-1.536, p=0.124$} \\
\hline & & $14.29 \%$ & $35.71 \%$ & $32.14 \%$ & $17.86 \%$ & \\
\hline & Yes & 3 & 9 & 7 & 13 & \\
\hline & & $9.38 \%$ & $28.13 \%$ & $21.88 \%$ & $40.63 \%$ & \\
\hline \multirow{4}{*}{$\begin{array}{l}\text { Regional LN } \\
\text { involvement }\end{array}$} & No & 5 & 17 & 7 & 1 & \multirow[t]{4}{*}{$Z=-4.814, p<0.001$} \\
\hline & & $16.67 \%$ & $56.67 \%$ & $23.33 \%$ & $3.33 \%$ & \\
\hline & Yes & 2 & 2 & 9 & 17 & \\
\hline & & $6.67 \%$ & $6.67 \%$ & $30.00 \%$ & $56.67 \%$ & \\
\hline
\end{tabular}

Z-U Mann-Whitney test, $H$-Kruskal-Wallis test, $R$-Spearman rank correlation. 

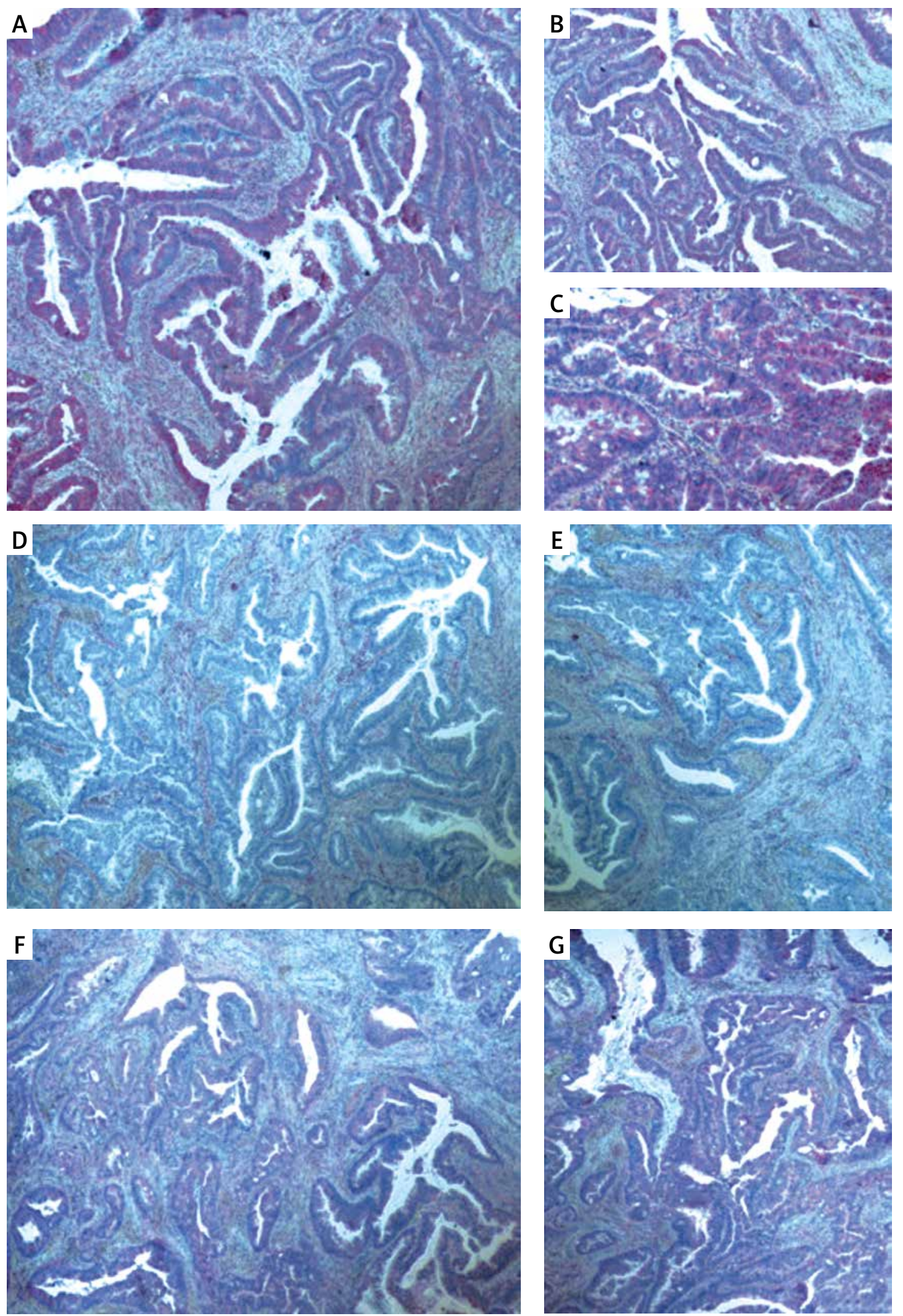

Figure 1. Representative examples of GAPDH (A-C), Bcl-2 (D, E) and Bax (F, G) protein immunoreactivity in G2 adenocarcinoma 
Table II. The association of Bcl-2 protein expression with clinicopathological features in CRC

\begin{tabular}{|c|c|c|c|c|c|c|}
\hline \multirow[t]{2}{*}{ Parameter } & & \multicolumn{4}{|c|}{ Bcl-2 expression } & \multirow[t]{2}{*}{ Statistical analysis } \\
\hline & & Negative & Weak & Moderate & High & \\
\hline \multirow[t]{4}{*}{ Age [years] } & \multirow[t]{2}{*}{$\leq 60$} & 5 & 5 & 6 & 11 & \multirow{4}{*}{$\begin{array}{l}Z=1.262, p=0.207 \\
R=-0.111, p=0.399\end{array}$} \\
\hline & & $18.52 \%$ & $18.52 \%$ & $22.22 \%$ & $40.74 \%$ & \\
\hline & \multirow[t]{2}{*}{$\geq 61$} & 7 & 11 & 7 & 8 & \\
\hline & & $21.21 \%$ & $33.33 \%$ & $21.21 \%$ & $24.24 \%$ & \\
\hline \multirow[t]{4}{*}{ Gender } & \multirow[t]{2}{*}{ Females } & 4 & 10 & 4 & 11 & \multirow[t]{4}{*}{$Z=0.720, p=0.471$} \\
\hline & & $13.79 \%$ & $34.48 \%$ & $13.79 \%$ & $37.93 \%$ & \\
\hline & \multirow[t]{2}{*}{ Males } & 8 & 6 & 9 & 8 & \\
\hline & & $25.81 \%$ & $19.35 \%$ & $29.03 \%$ & $25.81 \%$ & \\
\hline \multirow[t]{6}{*}{ Location of tumour } & \multirow{2}{*}{$\begin{array}{l}\text { Proximal } \\
\text { colon }\end{array}$} & 3 & 5 & 5 & 7 & \multirow[t]{6}{*}{$H(2.60)=1.278, p=0.528$} \\
\hline & & $15.00 \%$ & $25.00 \%$ & $25.00 \%$ & $35.00 \%$ & \\
\hline & \multirow[t]{2}{*}{ Distal colon } & 5 & 5 & 2 & 9 & \\
\hline & & $23.81 \%$ & $23.81 \%$ & $9.52 \%$ & $42.86 \%$ & \\
\hline & \multirow[t]{2}{*}{ Rectum } & 4 & 6 & 6 & 3 & \\
\hline & & $21.05 \%$ & $31.58 \%$ & $31.58 \%$ & $15.79 \%$ & \\
\hline \multirow[t]{6}{*}{ Grade } & \multirow[t]{2}{*}{ G1 } & 2 & 1 & 3 & 16 & \multirow{6}{*}{$\begin{array}{c}H(2.60)=21.241, p<0.001 \\
1-2,1-3 \\
R=-0.580, p<0.001\end{array}$} \\
\hline & & $9.09 \%$ & $4.55 \%$ & $13.64 \%$ & $72.73 \%$ & \\
\hline & \multirow[t]{2}{*}{ G2 } & 6 & 6 & 9 & 2 & \\
\hline & & $26.09 \%$ & $26.09 \%$ & $39.13 \%$ & $8.70 \%$ & \\
\hline & \multirow[t]{2}{*}{ G3 } & 4 & 9 & 1 & 1 & \\
\hline & & $26.67 \%$ & $60.00 \%$ & $6.67 \%$ & $6.67 \%$ & \\
\hline \multirow[t]{8}{*}{ Depth of invasion } & \multirow[t]{2}{*}{$\mathrm{T} 1$} & 1 & 1 & 3 & 8 & \multirow{8}{*}{$\begin{array}{c}H(3.60)=21.395, p<0.001 \\
1-3,1-4,2-3,2-4 \\
R=-0.573, p<0.001\end{array}$} \\
\hline & & $7.69 \%$ & $7.69 \%$ & $23.08 \%$ & $61.54 \%$ & \\
\hline & \multirow[t]{2}{*}{$\mathrm{T} 2$} & 2 & 2 & 4 & 10 & \\
\hline & & $11.11 \%$ & $11.11 \%$ & $22.22 \%$ & $55.56 \%$ & \\
\hline & T3 & 6 & 6 & 5 & 1 & \\
\hline & & $33.33 \%$ & $33.33 \%$ & $27.78 \%$ & $5.56 \%$ & \\
\hline & T4 & 3 & 7 & 1 & 0 & \\
\hline & & $27.27 \%$ & $63.64 \%$ & $9.09 \%$ & $0.00 \%$ & \\
\hline Size of primary & $\leq 10$ & 3 & 4 & 10 & 17 & $Z=4.343, p<0.001$ \\
\hline & & $8.82 \%$ & $11.76 \%$ & $29.41 \%$ & $50.00 \%$ & $R=-0.565, p<0.001$ \\
\hline & $\geq 11$ & 9 & 12 & 3 & 2 & \\
\hline & & $34.62 \%$ & $46.15 \%$ & $11.54 \%$ & $7.69 \%$ & \\
\hline Lymphovascular & No & 3 & 1 & 9 & 15 & $Z=4.076, p<0.001$ \\
\hline invasion & & $10.71 \%$ & $3.57 \%$ & $32.14 \%$ & $53.57 \%$ & \\
\hline & Yes & 9 & 15 & 4 & 4 & \\
\hline & & $28.13 \%$ & $46.88 \%$ & $12.50 \%$ & $12.50 \%$ & \\
\hline Regional LN & No & 5 & 0 & 7 & 18 & $Z=4.289, p<0.001$ \\
\hline involvement & & $16.67 \%$ & $0.00 \%$ & $23.33 \%$ & $60.00 \%$ & \\
\hline & Yes & 7 & 16 & 6 & 1 & \\
\hline & & $23.33 \%$ & $53.33 \%$ & $20.00 \%$ & $3.33 \%$ & \\
\hline
\end{tabular}

Z-U Mann-Whitney test, $H$ - Kruskal-Wallis test, $R$-Spearman rank correlation. 
Table III. The association of Bax protein expression with clinicopathological features in CRC

\begin{tabular}{|c|c|c|c|c|c|c|}
\hline \multirow[t]{2}{*}{ Parameter } & & \multicolumn{4}{|c|}{ Bax expression } & \multirow[t]{2}{*}{ Statistical analysis } \\
\hline & & Negative & Weak & Moderate & Strong & \\
\hline \multirow[t]{4}{*}{ Age } & \multirow[t]{2}{*}{$\leq 60$} & 4 & 8 & 7 & 8 & \multirow{4}{*}{$\begin{array}{c}Z=1.336, p=0.182 \\
R=-0.179, p=0.172\end{array}$} \\
\hline & & $14.81 \%$ & $29.63 \%$ & $25.93 \%$ & $29.63 \%$ & \\
\hline & \multirow[t]{2}{*}{$\geq 61$} & 8 & 13 & 5 & 7 & \\
\hline & & $24.24 \%$ & $39.39 \%$ & $15.15 \%$ & $21.21 \%$ & \\
\hline \multirow[t]{4}{*}{ Gender } & \multirow[t]{2}{*}{ Females } & 6 & 11 & 6 & 6 & \multirow[t]{4}{*}{$Z=-0.569, p=0.569$} \\
\hline & & $20.69 \%$ & $37.93 \%$ & $20.69 \%$ & $20.69 \%$ & \\
\hline & \multirow[t]{2}{*}{ Males } & 6 & 10 & 6 & 9 & \\
\hline & & $19.35 \%$ & $32.26 \%$ & $19.35 \%$ & $29.03 \%$ & \\
\hline \multirow[t]{6}{*}{ Location of tumour } & \multirow[t]{2}{*}{ Proxima colon } & 2 & 6 & 6 & 6 & \multirow[t]{6}{*}{$H(2.60)=2.465, p=0.292$} \\
\hline & & $10.00 \%$ & $30.00 \%$ & $30.00 \%$ & $30.00 \%$ & \\
\hline & \multirow[t]{2}{*}{ Distal colon } & 6 & 7 & 2 & 6 & \\
\hline & & $28.57 \%$ & $33.33 \%$ & $9.52 \%$ & $28.57 \%$ & \\
\hline & \multirow[t]{2}{*}{ Rectum } & 4 & 8 & 4 & 3 & \\
\hline & & $21.05 \%$ & $42.11 \%$ & $21.05 \%$ & $15.79 \%$ & \\
\hline \multirow[t]{6}{*}{ Grade } & \multirow[t]{2}{*}{ G1 } & 3 & 4 & 6 & 9 & \multirow{6}{*}{$\begin{array}{c}H(2.60)=9.055, p=0.011 \\
1-3 \\
R=-0.388, p=0.002\end{array}$} \\
\hline & & $13.64 \%$ & $18.18 \%$ & $27.27 \%$ & $40.91 \%$ & \\
\hline & \multirow[t]{2}{*}{$\mathrm{G} 2$} & 4 & 9 & 5 & 5 & \\
\hline & & $17.39 \%$ & $39.13 \%$ & $21.74 \%$ & $21.74 \%$ & \\
\hline & \multirow[t]{2}{*}{ G3 } & 5 & 8 & 1 & 1 & \\
\hline & & $33.33 \%$ & $53.33 \%$ & $6.67 \%$ & $6.67 \%$ & \\
\hline \multirow[t]{8}{*}{ Depth of invasion } & \multirow[t]{2}{*}{$\mathrm{T} 1$} & 1 & 5 & 3 & 4 & \multirow{8}{*}{$\begin{array}{c}H(3.60)=9.529, p=0.023 \\
\sim 2-3,2-4 \\
R=-0.338, p=0.008\end{array}$} \\
\hline & & $7.69 \%$ & $38.46 \%$ & $23.08 \%$ & $30.77 \%$ & \\
\hline & \multirow[t]{2}{*}{$\mathrm{T} 2$} & 2 & 3 & 6 & 7 & \\
\hline & & $11.11 \%$ & $16.67 \%$ & $33.33 \%$ & $38.89 \%$ & \\
\hline & T3 & 5 & 9 & 1 & 3 & \\
\hline & & $27.78 \%$ & $50.00 \%$ & $5.56 \%$ & $16.67 \%$ & \\
\hline & $\mathrm{T} 4$ & 4 & 4 & 2 & 1 & \\
\hline & & $36.36 \%$ & $36.36 \%$ & $18.18 \%$ & $9.09 \%$ & \\
\hline Size of primary & $\leq 10$ & 6 & 8 & 8 & 12 & $Z=2.132, p=0.033$ \\
\hline tumour $[\mathrm{cm}]$ & & $17.65 \%$ & $23.53 \%$ & $23.53 \%$ & $35.29 \%$ & $R=-0.309, p=0.016$ \\
\hline & $\geq 11$ & 6 & 13 & 4 & 3 & \\
\hline & & $23.08 \%$ & $50.00 \%$ & $15.38 \%$ & $11.54 \%$ & \\
\hline Lymphovascular & No & 4 & 8 & 8 & 8 & $Z=1.470, p=0.141$ \\
\hline invasion & & $14.29 \%$ & $28.57 \%$ & $28.57 \%$ & $28.57 \%$ & \\
\hline & Yes & 8 & 13 & 4 & 7 & \\
\hline & & $25.00 \%$ & $40.63 \%$ & $12.50 \%$ & $21.88 \%$ & \\
\hline Regional LN & No & 3 & 4 & 8 & 15 & $Z=4.717, p<0.001$ \\
\hline involvement & & $10.00 \%$ & $13.33 \%$ & $26.67 \%$ & $50.00 \%$ & \\
\hline & Yes & 9 & 17 & 4 & 0 & \\
\hline & & $30.00 \%$ & $56.67 \%$ & $13.33 \%$ & $0.00 \%$ & \\
\hline
\end{tabular}

Z-U Mann-Whitney test, $H$-Kruskal-Wallis test, $R$-Spearman rank correlation. 
$p=0.023 ;$ Spearman $R=-0.338 ; p=0.008)$. In this case the higher level of Bax immunoexpression was demonstrated for patients with T2 invasion. Correlation was also detected between Bax immunoreactivity and size of primary tumour (Mann-Whitney $U$ test, $p=0.033$ ). Tumours not exceeding $10 \mathrm{~cm}$ tended to display higher immunoreactivity (Spearman $R=-0.309, p=0.016$ ). A statistically significant decrease in Bax immunoexpression was observed in relation to regional lymph node involvement. Bax immunoexpression was significantly higher in patients with negative lymph node (LN) status as compared to those with positive LN status (Mann-Whitney $U$ test, $p<0.001$ ).

\section{Correlations between expression of GAPDH, Bcl-2, and Bax protein}

Correlations were tested among GAPDH, $\mathrm{Bcl}-2$, and Bax protein expression. In order to explore this relationship, a significant negative Spearman correlation between GAPDH versus Bcl-2 protein $(R=-0.290, p=$ $0.025)$ and GAPDH versus $\operatorname{Bax}(R=-0.450, p<0.001)$ was demonstrated.

\section{Discussion}

Today it is widely accepted that cancer cells exhibit elevated aerobic glycolysis and rely more on this pathway to produce ATP and metabolic intermediates needed for cell proliferation [17]. GAPDH has been reported to participate in a wide range of cellular processes and may affect the activities of multiple interacting molecules. An increased level of GAPDH mRNA and protein has been detected in pancreatic cancer, lung cancer, and human prostate cancer of late pathological stage, suggesting that enhanced GAPDH expression may show connection with cell proliferation and cancer development [11, 21-25]. Nevertheless, several studies reported that GAPDH has been differentially expressed in renal cancer, breast cancer, prostatic cancer, liver cancer, colorectal cancer, bladder cancer, gastric cancer, melanoma, and glioma $[6,26]$.

The results of our study demonstrated that in patients with colorectal adenocarcinomas, expression of GAPDH protein was upregulated. We found a significant correlation between the grade of tumour and GAPDH immunoexpression. A significant difference was detected between the patients with $\mathrm{G} 1$ and those with $\mathrm{G} 3$ tumours. A higher level of GAPDH was observed in G3 patients. A significant correlation was also found between the level of GAPDH immunoexpression and size of primary tumours, and regional lymph node involvement. About $43 \%$ of patients with tumour size exceeding $10 \mathrm{~cm}$ showed a high level of GAPDH immunoreactivity. Moreover, in the group with positive regional lymph node involvement about $67 \%$ of patients demonstrated high expression of GAPDH protein, whereas in the group with negative status such high a level was described only in $18 \%$ of patients. These results may indicate that GAPDH is involved in colorectal cancer progression and metastasis.

Many studies have revealed that cancer is caused by alteration in the regulation and execution of programmed cell death [15]. The high level of GAPDH expression might benefit the relative suppression of apoptosis in cancerous tissues, favouring cancer cell survival and malignancy [6]. Evidence that GAPDH might be involved in apoptosis came from studies on cultured cerebellar neurons, showing that elevated level of GAPDH and subsequent translocation to the nucleus preceded neuronal death stimulated by culture aging or cytosine arabino nucleoside exposure [6]. Therefore, in this work we correlated expression of GAPDH protein with expression of $\mathrm{Bcl}-2$ and $\mathrm{Bax}$ at the level of immunohistochemistry.

In this context it should be mentioned that apoptotic signalling pathway is central to conserve a balance between cell death and survival and in keeping genome stability. As a rule, it is thought that the equilibrium between the rates of cell growth and apoptosis sustains intestinal epithelial homeostasis, and this stability is disturbed during cancer expansion [19, 20]. The signalling cascades regulating apoptosis progression have been extensively studied, and both extrinsic and intrinsic pathways have been described for apoptosis activation. The extrinsic pathway is activated by triggering cell death receptors on the cell surface, leading to activation of the apoptotic machinery. Intracellular stimuli including hypoxia and enhanced level of cellular oxidative stress are among the activators of intrinsic mitochondrial pathway [18]. This type of apoptosis is under the control of proteins from the Bcl-2 family. The protein $\mathrm{Bcl}-2$ is a key inhibitor of apoptosis, and its aberrant expression has been demonstrated in a wide range of solid tumours, including colorectal cancer. In non-pathological colon mucosa a high level of $\mathrm{Bcl}-2$ has been found at the level of base cells corresponding to progenitor cells [18]. The high level of $\mathrm{Bcl}-2 \mathrm{immu}-$ noreactivity is also characteristic for adenoma stage, suggesting that abnormal activation of $\mathrm{Bcl}-2$ gene may play a role during early carcinogenesis $[27,28]$. Belt et al. demonstrated that low level of $\mathrm{Bcl}-2$ expression has been connected with disease reoccurrence, mainly in stage III patients [29]. This finding may indicate that low expression of $\mathrm{Bcl}-2$ is thought to be associated with increased cancer cells death [30]. The results of our study showed a higher expression of $\mathrm{Bcl}-2$ in well-differentiated cancers. In patients with G1 tumours, about 
$72 \%$ demonstrated a high level of expression, whereas in the group with $\mathrm{G} 3$, only $7 \%$ demonstrated a high level of $\mathrm{Bcl} 2$ immunoreactivity. It should be pointed out that there was a negative Spearman correlation between the expression of $\mathrm{Bcl}-2$ protein and grade of tumour, depth of invasion, and size of primary tumours. These results may suggest that $\mathrm{Bcl}-2$ is involved in early stages of colorectal carcinogenesis. Interestingly, in patients without lymphovascular invasion and with negative lymph node status, expression of $\mathrm{Bcl}-2$ was also characterised as high.

Bax protein is a homologue of $\mathrm{Bcl}-2$, which promotes apoptosis. Bax may bind to Bcl-2 forming Bax/ $\mathrm{Bcl} 2$ heterodimers, or it may bind to itself forming Bax/ Bax homodimers. The ratio of $\mathrm{Bax}$ to $\mathrm{Bcl}-2$ determines the susceptibility of a cell to apoptosis. Thus, in cells with Bax overexpression, Bax homodimers predominate, and the susceptibility of such cells to apoptotic stimuli is increased [31, 32]. Statistical analysis showed a significant negative correlation between Bax expres sion and grade of tumour, depth of invasion, size of primary tumours, and regional lymph node involvement. Similar to Sturm et al. [33], we also showed that Bax expression in primary tumours decreased from well differentiated (37.52\%) to poorly differentiated (20.60\%), indicating that Bax expression is involved in tumour differentiation. Pryczynicz et al. demonstrated that the frequencies of cases with stronger staining were dramatically decreased in metastases in the regional lymph nodes compared with those of primary tumours [34]. Low expression of Bax has been correlated with greater depth of tumour invasion, lymph vessel invasion, advanced stage, and worse prognosis. Regarding Bax expression in colorectal carcinomas, previous studies have demonstrated that Bax expression is related to marginally better or longer survival $[35,36]$, whereas in others it has been connected with poorer survival [37]. It is worth noting that Bax promotes apoptosis following genotoxic damage from either chemotherapy or irradiation; therefore, the presence of Bax might be associated with better prognosis [38].

For protein-protein interaction, a statistically significant negative correlation was observed between GAPDH and $\mathrm{Bcl}-2$. Interestingly, in the current study, GAPDH up-regulation is connected with down-regulation of $\mathrm{Bcl}-2$ expression. Similar results have been obtained when GAPDH protein was correlated with Bax. Up-regulation of GAPDH protein and down-regulation of apoptosis-associated proteins may show correlation with increased proliferation and survival of colon cancerous cells, resulting in aggressiveness of cancer. These results reinforce the assumption of similar behaviour of association of $\mathrm{Bcl}-2$ and Bax expression with grade of tumour, depth of invasion, and regional lymph node status. We observed a significant negative correlation between expression of apoptosis-related proteins and such clinicopathological parameters.

\section{Conclusions}

Results of our study have shown that that GAPDH, which is the main marker of glycolysis, is upregulated. We revealed significant positive correlation between expression of this protein and grade and size of tumour, as well as regional lymph node involvement. These results may indicate that GAPDH is involved in colorectal cancer progression and metastasis. In the case of apoptosis-associated proteins, e.g. Bcl-2 and Bax, we found negative correlations between expression of these proteins and such clinicopathological parameters as grade and size of tumour, lymphovascular invasion, and regional lymph node involvement. Finally, we demonstrated that GAPDH up-regulation is connected with down-regulation of $\mathrm{Bcl}-2$ and Bax protein expression at the level of immunohistochemical study.

The mechanism of apoptosis in colorectal cancer is a complex process that depends on many factors including hypoxia and oxidative stress. Although a great number of studies have been performed in recent years, the mechanisms implicated in the pathogenesis of colorectal cancer are still not completely known. A better understanding of these issues, especially in the context of altered glucose metabolism and hypoxic tumour environment, could result in more precise assessment of diagnosis and more effective treatment. Studies of this type should be continued, and new insight may in the future result in targeted therapy or possibly prevention.

\section{Acknowledgments}

The study was supported by grant KNW-1-043/ N/5/O of the Medical University of Silesia.

We would like to express my gratitude to M.Sc. M. Michalski for his skilled technical assistance.

\section{Conflict of interest}

The authors declare no conflict of interest.

\section{References}

1. Lee YC, Lee YL, Chuang JP, Lee JC. Differences in survival between colon and rectal cancer from SEER data. PLoS One 2013; 8: e78709.

2. Garza-Treviño EN, Said-Fernández SL, Martínez-Rodríguez HG. Understanding the colon cancer stem cells and perspectives on treatment. Cancer Cell Int 2015; 15: 2.

3. Hsu PP, Sabatini DM. cancer cell metabolism. Warburg and beyond. Cell 2008; 134: 703-7. 
4. Liberti MV, Locasale JW. The Warburg effect: how does it benefit cancer cells? Trends Biochem Sci 2016; 41: 211-8.

5. Ganapathy-Kanniappan, Geschwind JFH. Tumour glycolysis as a target for cancer therapy: progress and prospects. Mol Cancer 2013; 12: 152.

6. Guo C, Liu S, Sun MZ. Novel insight into the role of GAPDH playing in tumor. Clin Transl Oncol 2013; 15: 167-72.

7. Seidler NW. GAPDH: biological properties and diversity. Adv Exp Med Biol 2013; 985: 61-94.

8. Revillion F, Pawlowski V, Hornez L, Peyrat JP. Glyceraldehyde-3-phosphate dehydrogenase gene expression in human breast cancer. Eur J Cancer 2000; 36: 1038-42.

9. Colell A, Ricci J, Green DR, Ricci J. Novel roles for GAPDH in cell death and carcinogenesis. Cell Death Differ 2009; 16: 1573-81.

10. Huang Q, Lan F, Zheng Z, et al. AKT2 suppresses GAPDH mediated-apoptosis in ovarian cancer cells via phosphorylating GAPDH at threonine 237 and decreasing its nuclear translocation. J Biol Chem 2011; 286: 42211-20.

11. Rondinelli RH, Epner DE, Tricoli JV. Increased glyceraldehydes-3-phosphate dehydrogenase gene expression in late pathological stage human prostate cancer. Prostate Cancer Prostatic Dis 1997; 1: 66-72.

12. Dastoor Z, Dreyer JL. Potential role of nuclear translocation of glyceraldehydes-3-phosphate dehydrogenase in apoptosis and oxidative stress. J Cell Sci 2001; 114: 1643-53.

13. Chuang DMM, Hough C, Senatorov VV. Glyceraldehyde-3-phosphate dehydrogenase, apoptosis, and neurodegenerative diseases. Annu Rev Pharmacol Toxicol 2005; 45: 269-90.

14. Tatton NA. Increased caspase 3 and Bax immunoreactivity accompany nuclear GAPDH translocation and neuronal apoptosis in Parkinson's disease. Exp Neurol 2000; 166: 29-43.

15. Brown JM, Attradi LD. The role of apoptosis in cancer development and treatment response. Nat Rev Cancer 2005; 5: 231-7.

16. Huerta S, Goulet EJ, Livingston EH. Colon cancer and apoptosis. Am J Surg 2006; 191: 517-26.

17. Collel A, Green DR, Ricci JE. Novel roles for GAPDH in cell death and carcinogenesis. Cell Death Differ 2009; 16: 1573-81.

18. Hang HS, Park YM, Hwang TS. Differential expression of $\mathrm{BCl}-2$, $\mathrm{Bcl}-\mathrm{X}_{\perp}$ and $\mathrm{p} 53$ in colorectal cancer. J Gastroenterol Hepato 2006; 21: 1108-114.

19. Wilson TR, Johnston PG, Longley DB. Anti-apoptotic mechanisms of drug resistance in cancer. Curr Cancer Drug Targets 2009; 9: 307-19.

20. Lee MR, Ji SY, Mia-Jan K, Cho MY. Chemoresistance of CD133(+) colon cancer may be related with increased survivin expression. Biochem Biophys Res Commun 2015; 463: 229-34.

21. Schek N, Hall BL, Finn OJ. Increased glyceraldehydes-3-phosphate dehydrogenase gene expression in human pancreatic adenocarcinoma. Cancer Res 1988; 48: 6354-9.

22. Phadke M, Krynetskaia N, Mishra A, Krynetskiy E. Accelerated cellular senescence phenotype of GAPDH-depleted human lung carcinoma cells. Biochem Biphys Res Commun 2011; 411: 409-15.

23. Tokunaga K, Nakamura Y, Sakata K, et al. Enhanced expression of glyceraldehydes-3-phosphate dehydrogenase gene in human lung cancers. Cancer Res 1987; 47: 5616-9.

24. Wang D, Zhang G. High expression of GAPDH is relevant to lung adenocarcinoma with low expression of the tumour suppressor gene deleted in liver cancer-1 (DLC1). Cancer Res 2014; 74 (19 Suppl): A2367.

25. Harada N, Yasunga R, Higashimura Y, et al. Glyceraldehyde-3-phosphate dehydrogenase enhancer transcriptional activity of androgen receptor in prostate cancer cells. J Biol Chem 2007; 282: 22651-61.

26. Zhang JY, Zhang F, Hong CQ, et al. Critical protein GAPDH and its regulatory mechanism in cancer cells. cancer Biol Med 2015; 12: 10-22.

27. Krajewska M, Moss SF, Krajewski S, et al. Elevated expression of $\mathrm{Bcl}-\mathrm{X}$ and reduced Bak in primary colorectal adenocarcinoma. Cancer Res 1996; 15: 2422-7.

28. Watson AJ, Merritt AJ, Jones LS, et al. Evidence of reciprocity of bcl-2 and p53 expression in human colorectal adenomas and carcinomas. Br J Cancer 1996; 73: 889-95.

29. Belt EJT, Stockmann HBAC, Delis-Van Diemen PM, et al. Expression of apoptosis regulating proteins identifies stage II and III colon cancer patients with high risk of recurrence. J Surg Oncol 2014; 109: 255-65.

30. Poincloux L, Durando X, Seitz JF, et al. Loss of Bcl-2 expression in colon cancer: a prognostic factor for recurrence in stage II colon cancer. Surg Oncol 2009; 18: 357-65.

31. Wincewicz A, Sulkowska M, Koda M, et al. Significant coexpression of GLUT-1, Bcl-xL, and Bax in colorectal cancer. Ann N Y Acad Sci 2007; 1095: 53-61.

32. Wincewicz A, Sulkowska M, Koda M, Sulkowski S. Cumulative expression of HIF-1-alpha, Bax, Bcl-xL and P53 in human colorectal cancer. Pathology 2007; 39: 334-8.

33. Sturm I, Kohne CH, Wolff G, et al. Analysis of the p53/BAX pathway in colorectal cancer: low BAX is negative prognostic factor in patients with resected liver metastases. J Clin Oncol 1999; 17: 1364-74

34. Pryczynicz A, Gryko M, Niewiarowska K, et al. Bax protein may influence the invasion of colorectal cancer. World J Gastroenterol 2014; 20: 1305-10.

35. Huang CL, Kohno N, Inufusa $\mathrm{H}$, et al. Overexpression of Bax associated with mutations in the loop- sheet-helix motif of P53. Am J Pathol 1999; 155: 955-65.

36. Ogura E, Senzaki H, Yamamoto D, et al. Prognostic significance of $\mathrm{Bcl}-2, \mathrm{Bcl}-\mathrm{xL} / \mathrm{S}$, Bax and Bak expression in colorectal carcinomas. Oncol Rep 1999; 6: 365-9.

37. Saleh HA, Jackson H, Khatib G, Banerjee M. Correlation of bcl-2 oncoprotein immunohistochemical expression with proliferation index and histopathologic parameters in colorectal neoplasia. Pathol Oncol Res 1999; 5: 273-9.

38. Pietrantonio F, Biondani P, Ciurlia E, et al. Role of BAX for outcome prediction in gastrointestinal malignancies. Med Oncol 2013; 30: 610.

Received: 30.08 .2018

Accepted: 7.10.2018 